\title{
Monetary Policy and Large Crises in a Financial Accelerator Agent-Based Model
}

\author{
Federico Giri* $\quad$ Luca Riccetti ${ }^{\dagger} \quad$ Alberto Russo ${ }^{\ddagger}$ \\ Mauro Gallegati §
}

November 28, 2017

\begin{abstract}
An accommodating monetary policy followed by a sudden increase of the short term interest rate often leads to a bubble burst and to an economic slowdown. Two examples are the Great Depression of 1929 and the Great Recession of 2008. Through the implementation of an Agent Based Model with a financial accelerator mechanism we are able to study the relationship between monetary policy and large scale crisis events. A two-step computational approach is proposed which performs (i) a pattern search of "double dip" episodes and (ii) counter-factual simulations implementing unconventional monetary policy. The main results can be summarized as follow: a) sudden and sharp increases of the policy rate can generate recessions; b) after a crisis, returning too soon and too quickly to a normal monetary policy regime can generate a "double dip" recession, while c) keeping the short term interest rate anchored to the zero lower bound in the short run can successfully avoid a further slowdown.
\end{abstract}

Keywords: Monetary Policy, Large Crises, Agent Based Model, Financial Accelerator, Zero Lower Bound.

JEL classification codes: E32, E44, E58, C63.

\footnotetext{
${ }^{*}$ Corresponding author: Department of Economics and Social Sciences, Universitá Politecnica delle Marche, Piazzale Martelli 8, Ancona, Italy. E-mail: f.giri@univpm.it.

${ }^{\dagger}$ Department of Economics and Law, Universitá degli Studi di Macerata, via Crescimbeni 14, Macerata, Italy.

${ }^{\ddagger}$ Department of Managment, Universitá Politecnica delle Marche, Piazzale Martelli 8, Ancona, Italy.

${ }^{\S}$ Department of Managment, Universitá Politecnica delle Marche, Piazzale Martelli 8, Ancona, Italy.
} 


\section{Introduction}

Understanding the role played by monetary policy before and in the aftermath of a great economic downturn is not an easy task. Looking at an historical perspective of the last 400 years of economic crises and 23 bubble episodes, Brunnermeier and Schnabel (2016) documented that the combination of a long-lasting accommodating monetary policy just followed by a sharp and quick monetary contraction results to be a common powerful destabilizing mechanism of 21 of the events taken into consideration in the sample. ${ }^{1}$ As a result of "loose" monetary policy, credit grows, fueling bubbles on the housing and/or the stock market (see Bordo and Landon-Lane, 2013 and Ferrero, 2015). As highlighted by Fratianni and Giri (2017), the Great Financial Crisis of 2007/2008 adheres to such scheme. ${ }^{2}$

Figure 1 shows the period 2001-2004 when the fed funds rate was well below, almost 300 basis points at the end of 2004, the value predicted using a standard Taylor rule (Taylor, 2009, pag 3, Fig 1) suggesting that monetary policy was accommodating. The reason of such an aggressive expansionary monetary policy can be traced back to the burst of the "dot com" bubble in 2000-2001. The following recession forced the Federal Reserve to take drastic measures in order to restore the normal functioning of the US economy. At the end of 2004, concerns about a possible resurgence of inflation (Bernanke,

\footnotetext{
${ }^{1}$ The event taken in consideration are the following: the Mississippi bubble (1719-1720, France), Crisis of 1772 (England), Latin America Mania (1824-1825, England), Railway Mania (1847, England), Panic of 1857 (United States), Grunderkrise (1872-73, Germany and Austria), Chicago real estate boom (1881-83), Crisis of 1882 (France), Panic of 1893 (Australia), Norwegian crisis (1895-1900), Real estate bubble in the US (1920-26), German stock price bubble (1927), The Japanese "Lost decade" (1985-2003), Scandinavian crisis (1984-92), Thailand in the Asian crisis (95-98), Dot-com bubble (1995-2001), Real estate bubble in Australia (2002-04), Spanish housing bubble (1997-...). See Brunnermeier and Schnabel (2016, Appendix I) for a complete list.

${ }^{2}$ Non-monetary explanation are available, especially for the interpretation of the Great Depression. In particular, Temin (1976) focus its attention on the decline of consumption. Similarly, Romer (1990) underlines the role played by the decline in consumption of durable goods. Gordon and Wilcox (1981) focus his attention on the contraction of housing construction activity in the US. More recently, in the same context, Delli Gatti et al. (2012) highlighted the importance of technological changes, especially in the agricultural sector.
} 
Figure 1

Taylor rule and actual fed funds rate

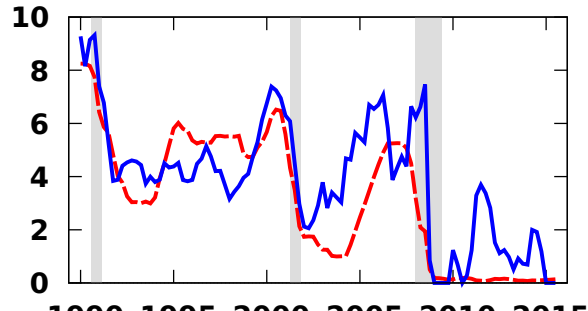

Gilchrist-Zakrajsek spread

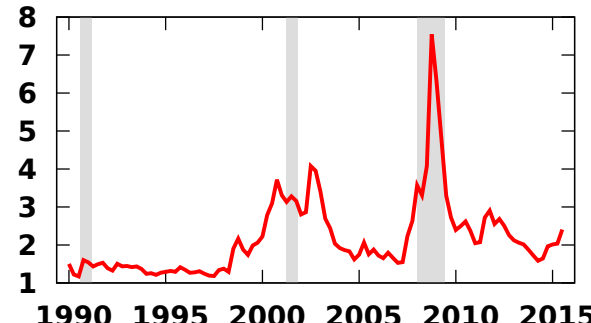

Excess bond premium

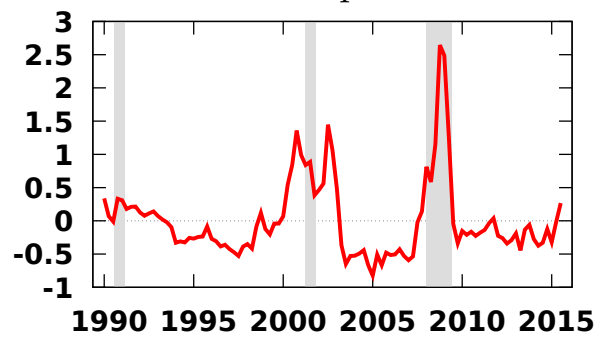

Source: FRED database, authors calculations and Gilchrist and Zakrajsek (2012). Left graph: the expression of the Taylor rule is taken from Taylor $(1993) . i_{t r}=\max \{0,4 \%+$ $\left.1.5\left(\pi_{t}-2 \%\right)+0.5 \widetilde{y}\right\}$. The red dashed line represents the effective fed funds rate, the blue line are the values predicted according to the Taylors rule. Grey bars represent recessions according to the NBER classification. The Gilchrist-Zakrajsek spread (henceforth GZ) is defined as "the average credit on senior unsecured bonds issued by non financial firms" while the excess bond premium can be considered a measure of risk default. The update series till August 2016 can be freely downloaded from Simon Gilchrist's webpage.

2005) convinced the governor of the Fed, Alan Greenspan, to abandon the accommodating monetary policy. Fed funds rate rose sharply from a value slightly above $1 \%$ to $5.25 \%$ in less than two years with the final results of spurring the external cost of fundings for both firms and private households (see second panel of Figure 1). The third panel of Figure 1 reports the excess bond premium calculated by Gilchrist and Zakrajsek (2012) from 1990 to 2015 as a measure of default risk. While the periods between 2001 and 2005 is characterized by a low perception of risk, the change of scenario at the end of 2006 caused an increase of default probability and the eruption of the sub-prime mortgages crisis (and, consequently, the end of the expansion of the American housing market). 
Monetary policy after the Great Recession changed radically. Extreme monetary policy measures were put in place pushing the interest rates closed to the zero lower bound of interest rates (henceforth ZLB). Once at the ZLB and the effectiveness of monetary policy based on steering the short term interest rates was undermined, central banks began to experiment unexplored way to stimulate the economy. ${ }^{3}$ As a consequence, understanding their effectiveness and consequences, both of ZLB and balance sheet policies, became a first order priority among both scholars and practitioners. For instance, Boeckx et al. (2017) and Weale and Wieladek (2016) exploit structural VAR in order to assess the macroeconomic effects of balance sheet operations by the ECB and the Bank of England, respectively. They both find substantial effects of central banks' unconventional monetary policies on GDP growth and inflation. On the other hand, Chen et al. (2012) use a NKM-framework in order to evaluate the Large-Asset Purchase program activated by the FED finding modest effect of such program on GDP growth and a negligible on inflation dynamics. Burlon et al. (2016) includes in their NKM not only the possibility of asset purchase by the central bank but they also introduce the so-called "Forward Guidance" of short term interest rate. The authors find that keeping the short term interest rates constant at a low level for a sufficient period of time (2 years) can help the effectiveness of asset purchase program in line with recent findings suggesting that the ZLB can enhance the effectiveness of unconventional monetary policy (see Gertler and Karadi, 2011).

Even if Agent Based Models (henceforth ABM) have been already used as computational tools to investigate economic policy issues, very few con-

\footnotetext{
${ }^{3}$ For instance, Fed, Bank of Japan (BoJ), Bank of England (BoE) and European Central Bank (ECB) perform several quantitative easing programs in order to reduce the medium term interest rate and to increase the value of the financial assets. Moreover, the ECB breaks the ZLB for marginal deposit operations since June 2014 (and now this interest rate is set at $-0.40 \%$ ) and it is now programming negative interest rates also for targeted longterm refinancing operations in order to subsidize banks to lend money to the non-financial sector.
} 
tributions focus their attention on unconventional monetary policy. ${ }^{4}$ Accordingly, the aim of this paper is to investigate unconventional monetary policies within an ABM framework augmented with a financial accelerator mechanism as in Bernanke et al. (1999) (henceforth BGG), that is the standard mechanism to introduce financial frictions in the classical DSGE models. The inclusion of the BGG financial accelerator mechanism is motivated by the importance of credit spreads in the development of 2007/2008 financial crisis (see second panel of Figure 1). In the original set up, the external finance premium applied by financial intermediaries on a loan is positively related to the amount of funds obtained by the firm and negatively with the available firm's net worth. As underlined by Quadrini (2011, p 215), the financial accelerator framework contains heterogeneity both at firms and at financial intermediaries level but, after linear aggregation, the equation describing the external risk premium collapse into an aggregate relationship. The extension of the financial accelerator into an ABM set up allow us potentially to take advantage of the entire heterogeneity of the original BGG framework. ${ }^{5}$

We use this new model to answer to three questions: a) in the spirit of Brunnermeier and Schnabel (2016), is there a macroeconomic relationship between monetary policy and large scale crisis events? b) Keeping the short

\footnotetext{
${ }^{4}$ The contribution of Lengnick and Wohltmann (2016) is one of the few that investigates both conventional and unconventional monetary policy in an hybrid set up that integrates a NKM with an agent-based model of the financial market finding that backward looking monetary rules can generate huge instability. In general, several works study policy issues in an agent-based model framework. A non-exhaustive list of contributions especially related with monetary policy is the following: Delli Gatti et al. (2005) explore the role of monetary policy focusing on agent's learning; Haber (2008) and Dosi et al. (2015) focus their attention on the role played by both fiscal and monetary policies and their relative interaction; Salle et al. (2013) underlines the role of inflation targeting for the conduction of monetary policy; da Silva and Lima (2015) studies the effect of monetary policy on financial regulation and vice-versa; Riccetti et al. (2013a) investigates the role of leverage in relationship with the effectiveness of monetary policy.

${ }^{5}$ An alternative specification to model financial frictions into a DSGE model is the Kiyotaki and Moore (1997) collateral constraint framework in which borrowers are limited in the amount of credit they can obtain by the available amount of collateral. However, Brzoza-Brzezina et al. (2013) find that the financial accelerator has better empirical performances in terms of dynamics of the variables.
} 
term interest rates close to the ZLB an effective tools of unconventional monetary policy? c) After a crisis, should the conduction of monetary policy return to a normal implementation as soon as possible or is it desirable to keep the interest rates close to the ZLB for an extended period of time to prevent a "double dip" recession?

In order to disentangle the effect of unconventional monetary policy we propose a new way to detect endogenous patterns within a complex economic system which is repeatedly simulated according to a Monte Carlo computational experiment. This is a particularly relevant point in that ABMs generate emergent properties that often are difficult to be identified accurately. This holds also for studying the effects of policy and then the identification of its effects on the economy. Standard macro model are characterized by the existence of a steady-state with some fluctuations around (perhaps amplified by some mechanism as the financial accelerator Bernanke et al. (1999)) and policy changes can be studied observing impulse-response functions as deviations from the known equilibrium. In ABMs this is not the case given that they feature disequilibrium dynamics and are characterized by alternate periods of stability, perhaps around a statistical equilibrium, and instability, as well as by endogenous large crises, as the result of the interaction of a multitude of heterogeneous agents. This leads to both pros and cons of ABM in economics. On the one hand, ABMs are able to jointly generate various phenomena, from micro to meso and macro stylized facts, without needing exogenous shocks to macro variables (like monetary or productivity shocks in NKM models), based on the evolution of agents' behavior and the collective dynamics which emerge from their interaction within markets, institutional and social structures. ABMs can both reproduce business cycle fluctuations as well as extended crises within the same simulation, as for instance in Riccetti et al. (2015). On the other hand, complex dynamics are difficult to be analyzed and some causal relationship, or the effect of 
some policy, may result unclear or at least not appropriately identified.

In ABMs it is not difficult to test alternative scenarios, for instance by running different simulations with different values of a parameter or modified versions of some (behavioral or policy) rules, when this is made from the beginning of the simulation. For the sake of clarity, think about two different scenarios which are experimented by performing two (battery of) simulations of the model, one with a standard Taylor rule and the other with an unconventional monetary policy. Different results should emerge from the two scenarios that might highlight some relevant features of (unconventional) monetary policy. It is much more difficult to test the role of, say, monetary policy when one wants to study different behaviors of the central bank which are related to the endogenous evolution of the system: to continue with our example, the central bank follows a standard Taylor rule under "normal conditions", while it wants to implement a ZLB unconventional policy during a prolonged recession, in order to avoid an excessive rise in unemployment (that could follow a policy rate hike in such a circumstance). Given that the realization of a prolonged recession scenario is due to the endogenous evolution of the system, namely it is not created by an exogenous shock, firstly we should look for this specific pattern (throughout the multiple simulations of the model) and, when the pattern is identified, we may implement different monetary policy rules over it.

Accordingly, the two building blocks of our computational approach are: (i) a pattern search to identify double dip episodes, and (ii) counter-factual simulations to assess the role of unconvetional monetary policy as opposed to a standard Taylor rule. The main findings are the followings: a) an increase of short term interest rates can generate a large scale crisis if the increase happens too quickly and too sharply; b) after a crisis, if the central bank returns too early to conduct monetary policy steering the short term interest rates, the possibility of falling in a "double dip" recession is significant, while 
c) keeping short term interest rates close to the zero lower bound helps the central bank to stabilize the economy, at least in the short run.

The paper is organized as follow: Section 2 presents the ABM model in details, while Section 3 shows the general properties of the model, the descriptions of a large-scale crisis event produced by the model and a counterfactual unconventional monetary policy experiment; the robustness of our findings are assessed through a comprehensive Monte Carlo computational experiment. Section 4 summarizes the main findings and the possible future developments of this work.

\section{The model}

In this section we provide a detailed description of the ABM we propose in order to analyze macroeconomic dynamics and, in particular, the behavior of the monetary authority during large crisis events. The model is an extension of the model presented in Riccetti et al. (2013, 2015). On the one hand, the current version of the model includes a new economic sector and a new market, that is the firms that produce capital goods and the capital goods market. On the other hand, in order to reduce the complexity of the simulation, the current model eliminates the heterogeneity of the financial sector creating an aggregate banking system.

It is worth to notice that model dynamics are not limited to the relationship between monetary policy and recessions. Indeed, the model is able to endogenously reproduce a variety of macroeconomic scenarios and different typology of crises, such as crises due to real factors.

In what follows, firstly, we briefly present the set up of the model (subsection 2.1; then, we provide a more detailed explanation of agents' behavior. 


\subsection{Model setup}

The economy evolves over a time span $t=1,2, \ldots, T$ and it is composed of households $(h=1,2, \ldots, H)$, capital goods firms $(k=1,2, \ldots, K)$, consumption goods firms $(f=1,2, \ldots, F)$, a banking system, a central bank, and the government. Agents are boundedly rational and live in an incomplete and asymmetric information context, thus they follow simple rules of behavior and use adaptive expectations.

Agents interact in the five markets reported in table 1.

Table 1: Markets included in the model

\begin{tabular}{lll}
\hline Market & Supply side & Demand side \\
\hline & & \\
Credit & Bank & Firms - government \\
Labor & Households & Capital goods firms - government \\
Capital goods & Capital goods firms - bank & Consumption goods firms \\
Consumption goods & Consumption goods firms - bank & Households \\
Deposits & Households & Bank \\
\hline
\end{tabular}

Credit and deposits markets are based on a centralized mechanism because in one of the market side there is the banking system, that is a single agent. Instead, in the other markets, the interaction mechanism that matches the demand and the supply sides follows the common decentralized matching protocol developed by Riccetti et al. (2015) and explained in appendix A-2. The price is set by the agents in the supply side and the agents in the demand side can choose the best offer.

The model works in the following way: first of all, firms borrow money from the banking system. Capital goods firms hire workers in order to produce and sell their output to consumption goods firms. Consumption goods firms buy capital goods to produce consumption goods and sell their output to households. Households sell labor, use their wage and profit income to buy consumption goods, and deposit their savings in the banking system. The banking system collects deposits in the end of a period and give credit 
to firms in the beginning of the next. However, the banking system is able to create money till a value equal to a multiple (endogenously set according to a rule that we will explain in Section 2.4) of its net worth. We separate the money collection and the lending activities with the help of the central bank: if the deposits are not enough, the banking system receives money injections from the central bank (in the opposite case, instead, the central bank collects the free reserves from the banking system). The credit lasts one period. Moreover, the banking system suffers non-performing loans for the fraction of loans not repaid by firms; however, the bank comes into the possession of firms' inventories of capital and consumption goods, that it tries to sell at a discounted price in the respective markets.

Another simplifying assumption is that consumption goods are produced by means of capital goods and that capital goods are produced only by employing labor. This assumption allows us to border the direct interaction between firms and workers in the labor market to one typology of firms, that is capital goods producers.

The government is a very relevant agent for the model because it also represents the non-industrial sector and, being a-cyclical, stabilizes the economy. It collects taxes and employs a fraction of the households. The public deficit is financed by issuing securities that are bought by the banking sector and, if the banking sector demand is not enough, by the central bank.

For a more detailed overview of the working of the model see Appendix A-3, in which the sequence of events that occurs in our economy is fully described. In next subsections, we describe in details the behavior of agents.

\subsection{Households}

As already explained, households perform the following main activities: (i) sell labor to capital goods producers, (ii) buy consumption goods, (iii) deposit their savings in the banking system. 
Therefore, households are on the supply side of the labor market, in which they interact according to the decentralized matching process described in Appendix A-2. Each worker posts a wage $w_{h t}$ that increases if she was employed in the previous period, and vice versa:

$$
w_{h t}= \begin{cases}w_{h t-1} \cdot(1+\alpha \cdot U(0,1)) & \text { if } h \text { employed at time } t-1 \\ w_{h t-1} \cdot(1-\alpha \cdot U(0,1)) & \text { otherwise }\end{cases}
$$

The required wage increases/decreases by a random percentage that ranges between zero and parameter $\alpha>0$ (indeed $U(0,1)$ is a random number extracted from a Uniform distribution). However, the requested wage has a minimum value which is tied to the price of one consumption good.

Due to mismatch in labor demand/supply and in wage offered/required, workers may remain unemployed. Unemployed people gain no labor income nor receive unemployment benefits.

Households pay a proportional tax on gross wage $w_{h t}^{\prime}$ so that the net labor income is equal to $w_{h t}=\left(1-\tau_{t-1}^{W}\right) w_{h t}^{\prime}$, where $\tau_{t-1}^{W}$ is set by the government in a way we will explain in Section 2.5.

In addition, households, proportionally to their wealth, receive the dividend distributed by firms and by the banking system. However, the total amount of resources needed to finance new entrants is subtracted from the flow of dividends.

The second (decentralized) interaction of households is in the consumption goods market, where households are on the demand side. Households set the desired consumption on the basis of their disposable income and wealth:

$$
c_{h t}^{d^{\prime}}=\max \left(\bar{p}_{t}, c_{w} \cdot w_{h t}+c_{a} \cdot a_{h t-1}\right)
$$

where $0<c_{w}<1$ and $0<c_{a}<1$ are the propensity to consume out of income and wealth, respectively, $a_{h t-1}$ is the net wealth accumulated 
till the previous period, and $\bar{p}_{t}$ is the average price of consumption goods. Accordingly, we assume that households desire to consume at least one good, therefore the level of the desired consumption is not smaller than the average price of one consumption good. Moreover, a budget constrain has to be considered as a household cannot spend more than available resources, given that consumer credit is not allowed in the model, so that the (financially constrained) desired consumption is: $c_{h t}^{d}=\min \left(c_{h t}^{d^{\prime}}, w_{h t}+a_{h t-1}\right)$.

At the end of the decentralized interaction process in the consumption goods market, each household ends up with a residual cash which does not cover the purchase of additional goods. This amount is considered as involuntary saving and is added to the voluntary saving. Indeed, the fraction of households' income and wealth which is not set for the desired consumption, the interest (net of taxes) received on the previous $\operatorname{deposit}^{6}$ and the distributed dividends form the voluntary saving, on which households pay a wealth tax at the fixed rate $\tau^{A}$. The household deposits the whole saving (net of the wealth tax) at the bank and this is the wealth available for the next period.

\section{$2.3 \quad$ Firms}

In the model there are two kind of firms: capital and consumption goods producers. Now we describe the common features of both kind of firms, while Subsections 2.3.1 and 2.3.2 will explain the peculiar features of each kind of firm.

Capital goods producers perform the following main activities: (i) borrow money in the credit market, (ii) hire households in the labor market, (iii) produce capital goods, (iv) sell their output to consumption goods producers in the capital goods market.

Consumption goods producers perform the following main activities:

\footnotetext{
${ }^{6}$ The setting of the interest rate on deposits $i_{t}^{D}$ will be described in Section 2.4.
} 
borrow money in the credit market, (ii) buy capital goods in that market, (iii) produce consumption goods, (iv) sell their output to households in the consumption goods market.

The aim of both kinds of firms is to sell their production. Therefore, the first step is to set their desired level of sales, and consequently of production. From this value, capital goods producers compute the labor demand and the related expected wage bill, while consumption goods producers compute the desired capital goods demand. Consequently, they set their credit demand. These steps are here detailed described.

First of all, the firm has to set the desired level of sales. A firm decides to increase its sales if, in the previous period, it made positive profits and remained with few unsold goods compared to its production, and it decides to reduce its sales vice versa. For instance, the following equation reports the decision for capital goods producers that depends on past sales, profits and inventories:

$$
\bar{x}_{k t}^{d}= \begin{cases}\bar{x}_{k t-1} \cdot(1+\alpha \cdot U(0,1)), & \text { if } \pi_{k t-1}>0 \text { and } \hat{x}_{k t-1}<\psi \cdot x_{k t-1} \\ \bar{x}_{k t-1}, & \text { if } \pi_{k t-1}=0 \text { and } \hat{x}_{k t-1}<\psi \cdot x_{k t-1} \\ \bar{x}_{k t-1} \cdot(1-\alpha \cdot U(0,1)), & \text { if } \pi_{k t-1}<0 \text { or } \hat{x}_{k t-1} \geq \psi \cdot x_{k t-1}\end{cases}
$$

where $\bar{x}_{k t-1}$ represents the quantity of capital goods sold in the previous period, $\pi_{k t-1}$ is the previous period gross profit, $\hat{x}_{k t-1}$ are inventories of capital goods, $x_{k t-1}$ stays for past production, $0 \leq \psi \leq 1$ is a threshold for inventories compared to past production and, as in the other behavioral rules, $\alpha>0$ is the maximum percentage change of the target sales, while $U(0,1)$ is a uniformly distributed random number. The same mechanism holds for consumption goods producers.

Now, firms set the desired level of production and, consequently, capital goods producers compute the labor demand and the related expected wage 
bill, while consumption goods producers compute the desired capital goods demand, as explained in the respective subsections.

Given the amount of internal resources and the outstanding debt, the credit demand is given by the following equation:

$$
b_{k / f, t}^{d}=\max \left(0, \gamma_{k / f, t}^{d}-\gamma_{k / f, t-1}+\bar{b}_{k / f, t-1}\right)
$$

where $\gamma_{k / f, t-1}$ is the liquidity already available, and $\bar{b}_{k / f, t-1}$ is the debt needed by the firm to cover negative liquidity resulted in the previous period.

Then, the firms go to the credit market, where the banking system sets the supply of credit (and the interest rate). If the whole demand of credit (from both capital and consumption goods producers) is minor than the supply, the firms receive all the required amount, otherwise firms are credit rationed proportionally.

The liquidity available for a firm is given by the sum of initial liquidity, $\gamma_{k / f, t-1}$, and the loan provided by the bank, $b_{k / f, t}$. If such a loan does not cover at least the negative liquidity inherited from the previous period, the firm goes bankrupt, even if its net worth is positive. In other words, if the firm does not obtain at least $\bar{b}_{k / f, t-1}$ it goes bankrupt. Thus, this is a default due to a liquidity shortage. The other condition for bankruptcy is that the net worth of the firm is negative. In this case, the default is due to insolvency. Defaulted firms are inactive during the next phases of the current period and their inventories are repossessed by the bank, so that it can covers, at least partially, the loss due to non-performing loans generated by firm bankruptcies.

Firms try to sell on the market the current production and the inventories (if present), after fixing the price. The price is set with a mechanism based on production and selling performance of the previous period. The following equation shows the price setting of the capital goods producers, but the same 
holds for consumption goods producers $\left(p_{f t}^{\prime}\right)$.

$$
p_{k t}^{K^{\prime}}= \begin{cases}p_{k t-1}^{K} \cdot(1+\alpha \cdot U(0,1)) & \text { if } x_{k t}>0 \text { and } \hat{x}_{k t}=0 \\ p_{k t-1}^{K} \cdot(1-\alpha \cdot U(0,1)) & \text { otherwise }\end{cases}
$$

Therefore, the price increases if the firm sold all its current production plus inventories, and vice versa. The price will be in any case equal or higher than the average cost of production (plus the interest on the bank loan):

$$
p_{k t}^{K}=\max \left(p_{k t}^{K^{\prime}}, \frac{w b_{k t}+i n t_{k t}}{x_{k t}}\right)
$$

where $w b_{k t}$ is the wage bill and $i n t_{k t}$ represents the interest paid on the bank loan. Again, the same mechanism (with the cost of capital goods instead of the wage bill) holds for consumption goods producers.

Both capital goods and consumption goods markets work in the same way even if supply and demand sides are obviously different. The supply side of the capital goods market is composed of both capital goods producers and the bank (that sells capital goods repossessed after firm defaults), and the demand side is represented by consumption goods firms. Instead, the consumption goods market involves the households on the demand side, while the supply side is composed of both consumption goods producers and the bank. In both markets agents interact according to the decentralized matching mechanism. At the end of the decentralized interaction process, firms may remain with unsold goods (inventories) that they will try to sell in the next period. The number of capital goods sold by the $k$-th firm at time $t$ is $\bar{x}_{k t}$, while the number of consumption goods sold by the firm $f$ at time $t$ is $\bar{y}_{f t}$.

After the interaction in the markets, firms compute their gross profit. 
The following equation is related to capital goods producers:

$$
\pi_{k t}^{\prime \prime}=p_{k t}^{K} \cdot \bar{x}_{k t}-w b_{k t}-i n t_{k t}
$$

The net profit is $\pi_{k t}^{\prime}=\left(1-\tau_{t}^{K}\right) \pi_{k t}^{\prime \prime}$, where $\tau_{t}^{K}$ is the proportional tax rate set by the government according to a rule we will explain in Section 2.5. Negative profit is used to reduce the taxes on next positive profit. If the profit is positive, a fraction is distributed to households, proportionally to their wealth, as dividends. Subtracting the dividends div $v_{k t}$ to the profit net of tax, we obtain $\pi_{k t}$. In particular, the dividend distributed is equal to $d i v_{k t}=\eta_{k t-1} \pi_{k t}^{\prime}$, where $\eta_{k t-1}$ depends on the weight of indebtedness on firm's total liquidity, that is the fraction of profit to be distributed increases if the liquidity is larger than the bank loan, and vice versa:

$$
\eta_{k t}= \begin{cases}\min \left(1, \eta_{k t-1} \cdot(1+\alpha \cdot U(0,1))\right) & \text { if } \gamma_{k t}>b_{k t} \\ \min \left(1, \eta_{k t-1} \cdot(1-\alpha \cdot U(0,1))\right) & \text { otherwise }\end{cases}
$$

The same mechanisms for profits (with the cost of capital goods instead of the wage bill) and dividends hold for consumption goods producers.

Now, firms check the available liquidity:

$$
\gamma_{k / f, t}=\gamma_{k / f, t-1}+\pi_{k / f, t}-\bar{b}_{k / f, t-1}
$$

in case of a negative value, they will ask for a bank loan aimed at covering this imbalance. Therefore, the additional demand of credit, to be asked in the next period, is equal to:

$$
\bar{b}_{k / f, t}= \begin{cases}0 & \text { if } \gamma_{k / f, t} \geq 0 \\ -\gamma_{k / f, t} & \text { otherwise }\end{cases}
$$

And we set at zero $\gamma_{k / f, t}$ if it is negative. 
Finally, firms update their net worth, as explained in the respective subsections.

\subsubsection{Capital goods producers}

Starting from the desired sale (see Equation 3), the labor demand of capital goods producers is given by:

$$
l_{k t}^{d}=\max \left(1,\left\|\frac{\bar{x}_{k t}^{d}}{\phi_{L}}\right\|\right)
$$

where $\phi_{L}$ is an integer number representing the productivity of labor. Accordingly, all firms demand at least one worker in each time period.

Total financing required to hire workers depends on the expected wage bill as follows:

$$
\gamma_{k t}^{d}=l_{f t}^{d} w_{t-1}\left(1+\dot{w}_{t-1}\right)
$$

where $w_{t-1}$ is the average wage of the previous period and $\dot{w}_{t-1}$ is the last period wage inflation rate.

After the credit market matching, if the firm is not bankrupted, it uses the available liquidity to hire households in the labor market: the decentralized matching takes place. The firms try to hire the workers that require the lowest wage (and pay the required wage). Due to mismatch in labor demand/supply and in available liquidity versus required wage, firms may remain with unfulfilled vacancies.

Given the number of hired workers, capital goods are produced. The production of capital goods involves only labor as input in the following way:

$$
x_{k t}=\phi_{L} l_{k t}
$$

As previously explained, firms try to sell their productions and inventories and, after the decentralized matching, compute their profits and their 
liquidity. Finally, they update their net worth:

$$
a_{k t}=p_{k t}^{K} \cdot \hat{x}_{k t}+\gamma_{k t}-\bar{b}_{k t}
$$

where $p_{k t}^{K} \cdot \hat{x}_{k t}$ is the value of inventories. Therefore, the net worth is equal to the sum of the value of inventories plus the cash if positive, or the value of inventories less the amount given by net outstanding debt $\left(\bar{b}_{k t}\right)$.

\subsubsection{Consumption goods producers}

Firms that produce consumption goods use capital goods as the only factor of production. Capital goods $x_{f t-1}^{\prime \prime}$ owned by consumption goods producers depreciates at the rate $\delta$ :

$$
x_{f t}^{\prime \prime}=(1-\delta) x_{f t-1}^{\prime \prime}
$$

Consequently, the number of capital goods of the firm $f$ at the beginning of period $t$ is:

$$
x_{f t}^{\prime}=\left\|x_{f t}^{\prime \prime}\right\|
$$

where we use the round operator in Equation 16, because we assume that the number of capital goods has to be an integer ${ }^{7}$.

Starting from the desired level of sales (following the mechanism of Equation 3) and taking into account the level of inventories, firms decide their desired production as the consumption goods to be added to inventories,

\footnotetext{
${ }^{7}$ Obviously, in the depreciation process, we take into account the actual value of capital goods, e.g. without rounding to the nearest integer. In other words, while $x^{\prime}$ is an integer number representing the number of capital goods from the previous period to be used in production at time $t, x^{\prime \prime}$ is the actual value of capital goods that we use in the next period to compute the depreciation. Let's make a numerical example: suppose, for instance, that firm A has $x_{1}^{\prime \prime}=x_{1}^{\prime}=2$ capital goods at time 1 , and that the depreciation rate is $20 \%$. At the end of period 1, its capital goods are depreciated to $x_{2}^{\prime \prime}=1.6$. Therefore at period 2 , assuming no other capital goods purchase, it uses again $x_{2}^{\prime}=2$ capital goods. At the end of period 2, we depreciate the capital goods starting from 1.6 (and not from 2 again!) to $x_{3}^{\prime \prime}=1.28$, therefore firm $\mathrm{A}$ in period 3 has only $x_{3}^{\prime}=1$ capital good available for production. Indeed, if you depreciated $x^{\prime}$ and not $x^{\prime \prime}$, depreciation would be sterilized by rounding (in the previous example, the capital goods always remain at 2).
} 
considering that the lower bound for production depends on available capital goods (that is we assume a full employment of the available machineries without further investments):

$$
y_{f t}^{d}=\max \left(\bar{y}_{f t}^{d}-\hat{y}_{f t-1}, \phi_{K} x_{f t}^{\prime}\right)
$$

where $\phi_{K}$ is an integer number which represents the productivity of capital goods.

Afterwards, firms determine the demand for new capital goods to be used in the production of final goods:

$$
x_{f t}^{d}=\frac{y_{f t}^{d}}{\phi_{K}}-x_{f t}^{\prime}
$$

The total financing of desired production depends on the expected price of capital as follows:

$$
\gamma_{f t}^{d}=x_{f t}^{d} p_{t-1}^{K}\left(1+\dot{p}_{t-1}^{K}\right)
$$

where $p_{t-1}^{K}$ is the average price of capital in the previous period and $\dot{p}_{t-1}^{K}$ is the last period inflation rate of capital goods price.

After the credit market matching, if the firm is not bankrupted, it uses the available liquidity to buy capital goods in the market, as already explained. The number of capital goods bought by the $f$-th firm at time $t$ is $x_{f t}$.

Now, firms produce consumption goods by means of the available capital goods:

$$
y_{f t}=\phi_{K} \cdot\left(x_{f t}+x_{f t}^{\prime}\right)
$$

As for capital goods producers, consumption goods producers try to sell their productions and inventories and, after the decentralized matching, compute their profits and their liquidity. Finally, they update their net 
worth:

$$
a_{f t}=\hat{p}_{f t}^{K} \cdot x_{f t}^{\prime \prime}+p_{f t} \cdot \hat{y}_{f t}+\gamma_{f t}-\bar{b}_{f t}
$$

where $\hat{p}_{f t}^{K}$ is the weighted average price of capital paid during the decentralized matching by the $f$-th firm.

\subsection{The banking sector}

The banking sector performs the following main activities: (i) lends money to firms, (ii) lends money to the government buying its bonds, (iii) sells repossessed inventories of defaulted firms, (iv) collects households' deposits, (v) interacts with the central bank (receives or deposits money).

Consumption goods producers, capital goods producers and the banking system interact in the credit market. Summing up the credit demand of both capital goods producers and consumption goods producers we obtain the total demand of credit $B_{t}^{d}$. The banking system sets the credit supply $B_{t}^{s}$ depending on its net worth $A_{t}^{b}$ and the propensity to lend $\rho_{t}$ :

$$
B_{t}^{s}=\rho_{t} A_{t}^{b}
$$

The propensity to lend evolves as follows:

$$
\rho_{t}= \begin{cases}\rho_{t-1} \cdot \alpha_{B} \cdot(1+U(0,1)) & \text { if }\left(\text { int }_{t-1}-b a d_{t-1}+r e p_{t-1}\right) / A_{t-1}^{b}>i_{t-1}^{C B} \\ \rho_{t-1} & \text { if }\left(i n t_{t-1}-b a d_{t-1}+r e p_{t-1}\right) / A_{t-1}^{b}=i_{t-1}^{C B} \\ \rho_{t-1} \cdot \alpha_{B} \cdot(1-U(0,1)) & \text { if }\left(\text { int }_{t-1}-b a d_{t-1}+r e p_{t-1}\right) / A_{t-1}^{b}<i_{t-1}^{C B}\end{cases}
$$

where $\alpha_{B}>0$ is an adjustment parameter, int $_{t-1}$ represents the interest gained on loans to firms, $b a d_{t-1}$ stays for non-performing loans, $r e p_{t-1}$ is the gain obtained selling the repossessed inventories (both capital and con- 
sumption goods) in case of firm defaults, ${ }^{8}$ and $i_{t-1}^{C B}$ is the policy rate. In practice, given that we assume that the interest rate paid by government bonds is equal to the policy rate, the bank compares the remuneration of firm loans to the remuneration of government bonds $i^{C B}$ considered as an alternative investment.

Given $B_{t}^{d}$ and $B_{t}^{s}$, two cases can emerge: (i) if $B_{t}^{d} \leq B_{t}^{s}$ then all firms obtain the requested credit; in this case the bank employs the difference $B_{t}^{s}-B_{t}^{d}$ to buy government securities; (ii) if $B_{t}^{d}>B_{t}^{s}$ then firms are rationed proportionally to the ratio $B_{t}^{s} / B_{t}^{d}$.

As in Bernanke et al. (1999), the bank charges a risk premium on firm loans as follows:

$$
r p_{z t}=i_{t-1}^{C B} \cdot\left(\frac{a_{z t-1}}{b_{z t}}\right)^{\nu}
$$

where $z=f, k$ indexes a firm, $a_{z t-1}$ is the firm's net worth, and $\nu<0$ is the parameter that governs the financial accelerator mechanism. Therefore, a firm with a higher leverage (computed as the ratio between debt and net worth), that is a riskier firm, pays a higher interest rate.

Then, the interest rate charged on firm loans is: ${ }^{9}$

$$
i_{z t}=i_{t-1}^{C B}+r p_{z t}
$$

As already explained, firms can go bankrupt for liquidity or solvency problems. In this case their inventories (both consumption and capital goods) are repossessed by the bank, so that it can covers, at least partially, the loss due to non-performing loans generated by firm bankruptcies. The bank try to sell these inventories at a discounted price. For instance, for capital goods it sets a discounted price $\bar{p}_{t}^{K}$ by applying a markdown $\beta$ on the

\footnotetext{
${ }^{8}$ The value of the variable $r e p$ is given by the inventories repossessed by the bank in the last period and sold in the market at a discounted price (see below for the setting of that price).

${ }^{9}$ In the case the policy rate reaches the Zero Lower Bound, the interest rate on the firm $z$ is: $i_{z t}=\sigma \cdot\left(\frac{a_{z t-1}}{b_{z t}}\right)^{\nu}$, where $\sigma>0$ is a parameter.
} 
previous period lowest price $p_{t-1}^{K m i n}$, that is $\bar{p}_{t}^{K}=(1-\beta) \cdot p_{t-1}^{K m i n}$. The same holds for consumption goods inventories repossessed. If the bank remains with unsold goods these are eliminated without further costs to eliminate these goods (but also without the gain related to the sale, able to reduce the loss given default for the bank). The bank enters in the decentralized matching mechanisms as a firm but, given the discounted price, it is very unlikely that the bank does not sell all goods repossessed.

At the end of the period, the banking system receives the deposits of the household. On these deposits $D_{t}$, the bank pays an interest rate $i_{t}^{D}$ determined applying a mark down $\omega$ on the policy rate set by the central bank $i_{t}^{C B}$ :

$$
i_{t}^{D}=i_{t}^{C B}(1-\omega)
$$

The profit of the bank is given by:

$$
\pi_{t}^{b^{\prime \prime}}=i n t_{t}+i n t_{t}^{G}+i n t_{t}^{R E}+r e p_{t}-i_{t}^{D} D_{t}-i n t_{t}^{C B}-b a d_{t}
$$

where $i n t_{t}$ represents the interest on loans to both consumption and capital goods producers, $i n t_{t}^{G}$ is the interest on government bonds, $i n t_{t}^{R E}$ is the interest on reserves deposited at the central bank, rept stays for the money obtained selling the repossessed capital and consumption goods after firm's default, $i n t^{C B}$ is the interest rate on central bank's money injection, and $b a d_{t}$ refers to non-performing loans due to firms' default. The bank pays a proportional tax on positive profit at the rate $\tau_{t}^{B}$ (see below for its setting), so that the net profit is $\pi_{t}^{b^{\prime}}=\left(1-\tau_{t}^{B}\right) \pi_{t}^{b^{\prime \prime}}$. Negative profit is used to reduce the taxes on the next positive profit. If the profit is positive, a fraction of it, that is $d i v_{t}^{b}=\eta_{t-1}^{b} \pi_{t}^{b^{\prime}}$, is distributed as dividends to households, proportionally to their wealth. The factor $\eta_{t}^{b}$ evolves according to the evolution of 
the bank's profit rate and the balance sheet as follows:

$$
\eta_{t}^{b}= \begin{cases}\min \left(1, \eta_{t-1}^{b} \cdot\left(1+\alpha^{B} \cdot U(0,1)\right)\right) & \text { if } \frac{\pi_{t-1}^{b^{\prime \prime}}}{a_{t-1}^{b}}>\frac{\pi_{t-2}^{b^{\prime \prime}}}{a_{t-2}^{b}} \text { and } r e_{t-1}>0 \\ \min \left(1, \eta_{t-1}^{b} \cdot\left(1-\alpha^{B} \cdot U(0,1)\right)\right) & \text { otherwise }\end{cases}
$$

where $r e_{t-1}$ represents the banks' free reserves at the central bank. Therefore, the bank distributes more dividends if the growth of the profit rate is positive and it has reserves at the central bank, and vice versa. The bank's profit net of both tax and dividend is then $\pi_{t}^{b}=\pi_{t}^{b^{\prime}}-d i v_{t}^{b}$.

Based on the net profit, the bank updates its net worth: $a_{t}^{b}=a_{t-1}^{b}+\pi_{t}^{b}$.

Before interacting with the central bank, the bank's balance sheet presents firm loans and government securities on the assets side, households' deposits and the net worth on the liabilities' side. Depending on the combination of these variables, the bank either receives money injections (on which it pays an interest at the policy rate $i_{t}^{C B}$ ) or holds deposits in an account with the central bank (on which we assume it receives an interest at the rate $i_{t}^{C B}\left(1-\omega^{C B}\right)$, where $\omega^{C B}>0$ is a markdown).

\subsection{Government}

The government performs the following main activities: (i) hires household, (ii) collects taxes, (iii) issues bonds in order to finance its public debt.

First of all, the government hires a fraction $g$ of households picked at random from the whole population. The remaining part of households enters the labor market and follows the decentralized matching process, being available for working in private capital goods firms.

However, government's expenditure is not only given by the wage bill to pay public workers, indeed the government has to pay the interest on issued bonds (bought by the bank and/or by the central bank) and, in case of bank and/or firm defaults, if the aggregate dividend is not enough to cover the 
total net worth of entrants, the government intervenes paying the needed difference.

As for government's revenues, we consider tax revenues and the transfer from the central bank. ${ }^{10}$

The tax rate on agents' income evolves according to the following fiscal rule:

$$
\tau_{t}^{q}= \begin{cases}\tau_{t-1}^{q} \cdot\left[1+\alpha^{\tau} \cdot U(0,1)\right] & \text { if } \frac{P D e b t_{t}-1}{G D P_{t}-1}>\frac{P D e b t_{t-2}}{G D P_{t-2}} \\ \tau_{t-1}^{q} & \text { if } \frac{P D e b t_{t}-1}{G D P_{t}-1}=\frac{P D e b t_{t-2}}{G D P_{t-2}} \\ \tau_{t-1}^{q} \cdot\left[1-\alpha^{\tau} \cdot U(0,1)\right] & \text { otherwise }\end{cases}
$$

where the $q$ indexes the various agents composing the economy, that is capital goods firms, consumption goods firms, households and the banking sector. For each typology of agent a different tax rate is computed according to the above fiscal rule, that is the same rule is applied but for different random numbers. This means that if the ratio between the public debt and the GDP is increasing, then all agents will be taxed more but the tax rate can be different for each typology of agent, due to the sequence of random numbers.

The evolution of public debt, PDebt $t_{t}$ depends on the accumulation of deficits $P D e f_{t}$ (or surpluses, in these cases $P D e f_{t}$ is negative): $P D e b t_{t}=$ $P$ Debt $_{t-1}+P D e f_{t} .{ }^{11}$ Government securities are bought by the banking sector. If the private demand is not enough to cover the whole debt, then the central bank buys the difference.

\footnotetext{
${ }^{10}$ All in all, the interest paid by the government to the central bank is then repaid by the central bank to the government.

${ }^{11}$ If $P$ Debt $t_{t}$ becomes negative, this is considered as cash to be used in the next period to cover government expenditures.
} 


\subsection{Central bank}

The central bank sets the policy rate $i_{t}^{C B}$ according to the following Taylor rule:

$i_{t}^{C B}=\max \left(0, \bar{r}\left(1-\phi_{R}\right)+\phi_{R} i_{t-1}^{C B}+\left(1-\phi_{R}\right)\left(\phi_{\dot{p}}\left(\dot{p}_{t}-\dot{p}^{T}\right)-\phi_{U}\left(u_{t}-u^{T}\right)\right)\right)$

where $\bar{r}, \phi_{R}, \phi_{\dot{p}}, \phi_{U}$ are positive parameters, $\dot{p}$ and $u_{t}$ are the inflation and the unemployment rates at time $t$ respectively, $\dot{p}^{T}$ and $u^{T}$ are the central bank's targets for inflation and unemployment respectively. Similarly to Gerali et al. (2010), the parameter $\bar{r}$ represents the long run level of the short-term interest rate.

Based on the banking sector's balance sheet, the central bank either provides money injections or receives reserves. Finally, the central bank is committed to buy outstanding government securities for the fraction of public debt not covered by the the bank's demand.

\section{Simulation results}

We run 1000 Monte Carlo replications of the model. The length of each replication is 1000 periods with the first 300 draws used as transient and not taken into account in the simulation analysis. Firstly, we calibrate the parameters of the model (Section 3.1). Secondly, we assess the changes of some of the analyzed features of the model with respect to different values of the parameter $\nu$ related to the financial accelerator mechanism (Section ??). Thirdly, we present two alternative policy scenarios that can be implemented by the central bank once a large scale crisis event occurred (Section 3.2). The baseline scenario is consistent with the idea that the central bank has to switch back immediately to a conduction of monetary policy implemented following a standard Taylor rule. The alternative scenario is consistent with 
the possibility that the central bank can keep the short term interest rate close to the ZLB for several periods in the simulation.

\subsection{Simulations of the baseline model}

We calibrate the parameters of the model starting from the values of the parameters in Riccetti et al. (2015), and performing a grid search around these values in order to reproduce some stylized facts on economic mechanisms and empirical first and second moments of several variables of interest taken from US data. Table 2 reports the values of parameters used in the simulations.

Table 2: Calibrated parameters

\begin{tabular}{lll}
\hline Parameter & Definition & Value \\
\hline & & \\
$H$ & Number of households & 400 \\
$F$ & Number of consumption good producers & 50 \\
$C P$ & Number of capital good producers & 150 \\
$\phi_{L}$ & Labor productivity & 1 \\
$\phi_{K}$ & Capital productivity & 10 \\
$\nu$ & Financial accelerator parameter & -0.05 \\
$\sigma$ & Risk free rate under ZLB & 0.005 \\
$\delta$ & Depreciation rate of capital & 0.01 \\
$\psi$ & Inventory parameter & 0.1 \\
$\phi_{R}$ & Interest rate degree of stickiness & 0.8 \\
$\phi_{p}$ & Coeff. Inflation target & 1.5 \\
$\phi_{U}$ & Coeff. Unempl. target & 0.1 \\
$\bar{r}$ & Long run interest rate & 0.02 \\
$\dot{p}^{T}$ & Central Bank inflation target & 0.04 \\
$u^{T}$ & Central Bank unemployment target & 0.08 \\
$g$ & Public workers & 0.4 \\
$c_{a}$ & Propensity to consume out of income & 0.8 \\
$c_{w}$ & Propensity to consume out of wealth & 0.3 \\
$\beta$ & Discounted price mark down & 0.3 \\
$\omega$ & Deposits mark down & 0.2 \\
$\omega^{C B}$ & Deposits at central bank mark down & 0.6 \\
$\chi$ & Share of partners matching problems & 0.5 \\
$\alpha$ & Behavioral adjustment parameter & 0.1 \\
$\alpha^{T}$ & Fiscal rule adjustment parameter & 0.05 \\
$\alpha_{B}$ & Bank's adjustment parameter & 0.05 \\
$\tau^{A}$ & Wealth tax & 0.03 \\
\hline & &
\end{tabular}


Table 3 reports theoretical moments of our Monte Carlo simulations and the relative empirical counterparts taken from US data from 1990:Q1 to 2015:Q4. In general, the model presents a higher volatility with respect to the data due to the decision of linking employment to the sector of capital goods that is more volatile than consumption goods sector. Nevertheless, the model is able to replicate satisfactorily some stylized facts ${ }^{12}$ especially the ones related to interest rates and spreads. ${ }^{13}$ This latter result is clearly related to the presence of a financial accelerator mechanism in the model that amplifies business fluctuations through credit market interactions.

Table 3: Theoretical and empirical moments of Monte Carlo simulations

\begin{tabular}{lcccc}
\hline & \multicolumn{2}{c}{ Theoretical moments } & \multicolumn{2}{c}{ Empirical moments } \\
Variables & Mean & Standard deviation & Mean & Standard deviation \\
\hline Growth rate & 0.040 & 0.081 & 0.044 & 0.020 \\
Inflation & 0.039 & 0.069 & 0.024 & 0.011 \\
Policy rate & 0.023 & 0.024 & 0.032 & 0.024 \\
Unemployment rate & 0.120 & 0.150 & 0.061 & 0.016 \\
$i^{k}$ & 0.050 & 0.045 & 0.072 & 0.014 \\
$i^{f}$ & 0.080 & 0.063 & & \\
Spread: $i^{k}-i$ & 0.027 & 0.022 & 0.041 & 0.016 \\
Spread: $i^{f}-i$ & 0.056 & 0.031 & & \\
\hline
\end{tabular}

Note: empirical moments are calculated on US data, 1990:Q1-2015:Q4. Source: FRED database, see data appendix for a description of the data.

In the data the average level of the Baa bonds yield is about to the $7 \%$ on annual base very close to the value of $6.5 \%$ found in the model. The average level of the policy rate in the model $(2.3 \%)$ is slightly lower than the value

\footnotetext{
${ }^{12}$ Since the focus of the paper is not on a comprehensive empirical validation of simulation results through a precise matching of stylized facts, we do not elaborate further on this topic.

${ }^{13}$ Although the assumption that workers are employed only in the capital goods firms may lead to a certain loss of realism, for instance resulting in a higher volatility of unemployment, it does not prevent the model to qualitatively explain various characteristics of the business cycle. However, in order to reduce unemployment volatility, an alternative choice would be to increase the number of "public workers" to have a larger a-cyclical sector in the economy.
} 
obtained by the data (3.2\%) implying an average spread between corporate loans and the policy rate (4.2\%) very close to the empirical counterpart.

\subsection{Policy experiments}

In this section, we firstly describe the evolution of our economy applying a standard monetary policy based on the Taylor rule (Subsection 3.2.1). Given that our simulation results show how a sudden monetary policy tightness after a periods of prolonged low interest rates can have destabilizing effects on the whole economy, we compare these results with the output of an extended expansionary monetary policy. We qualitatively show how the implementation of the unconventional monetary policy can represent an effective alternative to the Taylor rule-like behavior in reducing unemployment within a heterogeneous interacting agents framework (Subsection 3.2.2). Indeed, after the great recession of 2008, the Federal Reserve brought the short term interest rate very close to the ZLB and it kept fix to zero until December 2015, the beginning of the so called "Yellen call" 14 According to the current President of the Minneapolis FED, Neel Kashkari, this choice avoided that millions of Americans became unemployed in the wake of the crisis. More precisely, based on Minneapolis FED's estimations ${ }^{15}$ if the Federal Open Market Committee (FOMC) had followed the Taylor rule over the past five years, 2.5 million more Americans would be out of work currently. ${ }^{16}$ In Subsection 3.2.3 more crisis episodes are considered to assess the robustness of our finding about the role of the monetary policy.

To perform the explained analysis, we study the evolution of our economy

\footnotetext{
14 "Forget the 'Greenspan put'; Fear the 'Yellen Call'", The Wall Street Journal, http://www.wsj.com/articles/how-the-yellen-call-will-keep-stocks-in-check-1457554210

${ }^{15}$ The simulations was performed by using the FRB/US model which is a large-scale estimated general equilibrium model of the U.S. economy that has been in use at the Federal Reserve Board since 1996. For more details, see https://www.federalreserve.gov/econres/us-models-about.htm

16 "Taylor Rule would have kept millions out of work", President Neel Kashkari on Medium.com, https://medium.com/@neelkashkari/taylor-rule-would-have-kept-millionsout-of-work-9ab31fd826bf
} 
using the time series of twelve simulated variables, shown in Figures 2 and 3: the policy rate and the corporate loans interest rates (both for capital producers and consumption goods producers), the unemployment rate, the GDP growth rate, the inflation rate, the quantity of capital recovered by the bank after firms' defaults, firms' real liquidity, the total loans and the amount of external funds that is needed to refinance firm's past debt, firms' net worth, the ratio between public debt and GDP, the production of capital and the relative stock of inventories, the ratio between bank's bad debt and the total amount of loans, the wage inflation.

\subsubsection{Baseline monetary policy: Taylor rule}

Figures 2 shows the evolution of our economy when a standard monetary policy based on the Taylor rule is applied. Central bank keeps the nominal interest rate quite low for about 20 periods in response to a previous slow down of the economy that determined an increase of the unemployment rate. The low level of the policy rate, very close to the ZLB, successfully restore full employment and high GDP growth. The stabilization of the economy is followed by an increase of loans provided by banks to the real economy and a reduction of the bad debt over the total amount of loans. Capital good producers restore the maximum production capability. Firm's net worth and the related available liquidity increase.

For several periods, unemployment rate is below the long run target of $8 \%$ specified by the monetary authority. After period $t=20$, the central bank starts to raise the short term interest rates in order to prevent an upturn of inflation. The increase of the short term interest rate is quite sharp, from a value very close to the ZLB to almost $4 \%$ in a short period of time, closely resembling the behavior of the Federal Reserve at the end of the so called "Greenspan put" at the end of 2006 in the US. The financial accelerator mechanism amplifies the external funding cost for both capital 
Figure 2: Monetary policy restriction
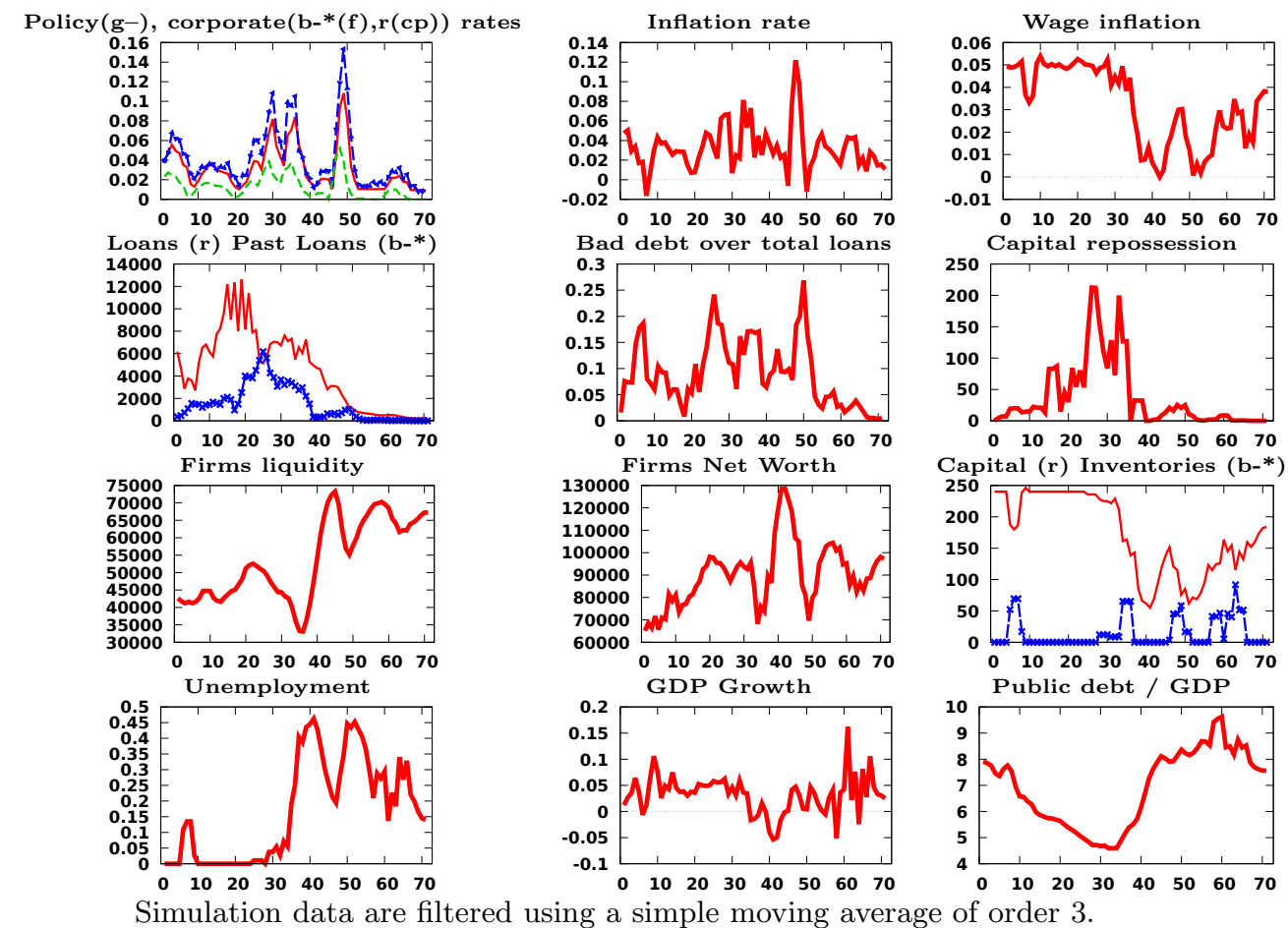

and consumption goods producers. Loans demand is negatively affected by the higher corporate interest rates and immediately begins to shrink. Moreover, the quantity of loans used to cover previous period debt start to increase suggesting that firms are in a "speculative" phase in line with the taxonomy proposed by Minsky in his financial instability hypothesis (see Minsky, 1986).

Real variables reacts accordingly to the negative financial conditions of the economy. The production of new capital decreases, negatively affecting GDP growth and wages. Public debt over GDP increase due to the contraction of the GDP.

\subsubsection{A counterfactual experiment: prolonged zero lower bound}

In this subsection we perform the counterfactual monetary policy experiment. In the alternative scenario the central bank starts to implement ZLB 
policy of the short term interest rates and keep it close to the ZLB for a prolonged period of time, differently from the baseline scenario in which the monetary authority steers short term interest rates following a classical Taylor rule. Figure 3 shows the counterfactual experiment. It is worth noticing that the plots displayed in Figure 3 refer to the same simulation presented in Figure 2, that is we add the scenario in which an unconventional monetary policy is implemented on the top of the baseline scenario in which the standard taylor rule is followed by the central bank.

The baseline scenario shows that a "double dip" recession is a major threat when the central bank starts to rise the short term interest rate too much and too early. Our main variable of interest is the unemployment rate that we use to detect the crises. Figure 3 shows a first peak of unemployment around period 40, followed by a period of economic recovery. Therefore, in the baseline scenario the interest rates are stuck for a short period close to the ZLB and than they start to rise again as soon as the economy begins to recover. However, the increase of the interest rates stops the growth phase causing a second peak of unemployment around period 50. The "double dip" crisis can be observed (even if it is less evident) also in the GDP growth panel: the growth rate goes below zero around period 40, turns positive at period 45 , but goes back toward zero around period 50 .

Instead, under the unlimited ZLB scenario, the central bank is able to stem the magnitude of the crisis, at least in the short run. Keeping the growth rate above the level of the baseline scenario, the central bank is able to stabilize the unemployment rate avoiding the second recession or a slowdown of the growth rate. Therefore, the central bank intervention through setting the policy rate near to the ZLB is successful in avoiding a second hump of the unemployment rate. The accommodating monetary policy is also capable of mitigating the credit crunch on the corporate loans market; a stabilization of the ratio of the bad debt over total loans, due 
Figure 3: ZLB vs no intervention by the central bank
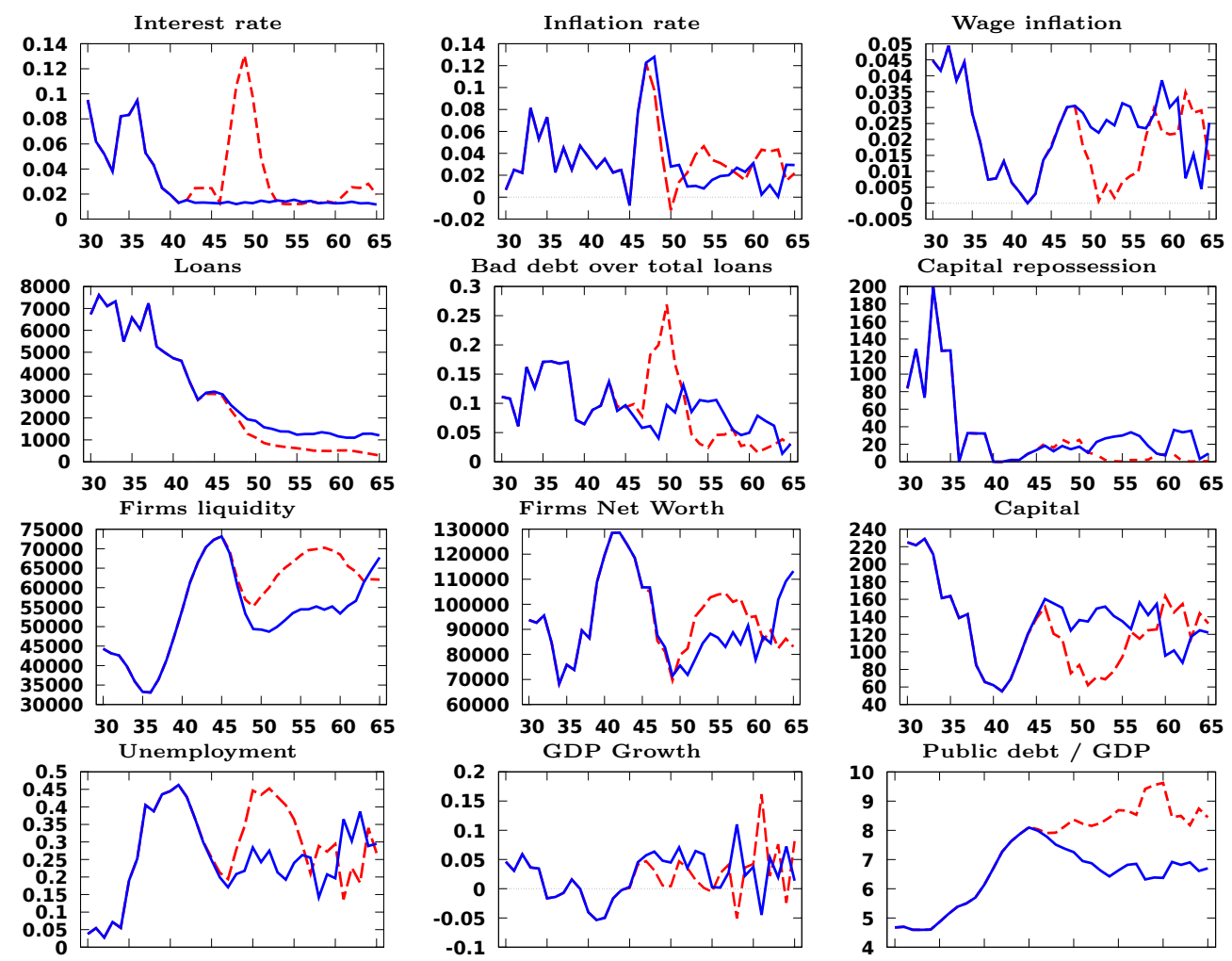

$\begin{array}{lllllllll}30 & 35 & 40 & 45 & 50 & 55 & 60 & 65\end{array}$
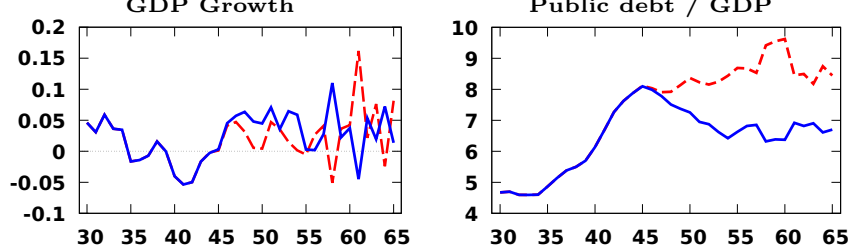

The red dashed line represents the scenario in which the central bank return to the standard Taylor rule immediately after the crisis while the blue line represents the zero

lower bound scenario. Simulation data are filtered using a simple moving average of order 3 .

to a lower level of bad debt and a higher level of extended loans, follows.

Another significant effect is the reduction of public debt over GDP in the ZLB scenario with respect to the baseline. The reduction of public debt is mainly due to both higher GDP growth and the lower interest rates paid on government bonds. ${ }^{17}$

\subsubsection{Taylor rule vs. ZLB across multiple simulations}

In what follows we provide a systematic investigation of the role of unconventional monetary policy as compared to the standard Taylor rule scenario

\footnotetext{
${ }^{17}$ The relatively low level of public debt over GDP could allow the government to further sustain the economy, unless its target is fiscal austerity.
} 
throughout the computational experiment, namely across 1000 Monte Carlo (MC) replications of the model. In other words, we look for episodes which exhibit a pattern similar to that described in the last subsection, and in each case we firstly observe the evolution of the economy under the standard Taylor rule and then we perform a counter-factual simulation in which the ZLB unconventional monetary policy is applied. The aim of this additional simulation step is then to assess the robustness of the previous finding, that under the ZLB scenario the central bank is able to avoid a "double dip" recession episode. In particular, we focus on the potential beneficial role of monetary policy in reducing unemployment by keeping the policy rate near zero as long as necessary.

The computational approach we propose in this paper, which combines pattern search and counter-factual simulations, allows us to (i) recognize a number of episodes with similar characteristics which endogenously emerge from model simulations (in our specific case, "double dip" episodes, and then (ii) to perform a computational experiment in which some treatment is analyzed (in our case, an unconventional monetary policy setting the policy rate at the ZLB as long as necessary) and this is contrasted to what happens in the baseline (non-treatment) scenario (in our case, when the central bank follows a standard Taylor rule).

In particular, we proceed by implementing the two following steps: a) a list of episodes is detected based on the algorithm proposed by Harding and Pagan (2002), which is typically used to recognize business cycle turning points; ${ }^{18}$ b) for each episode two simulations are compared, namely the one with the standard Taylor rule and the alternative scenario implementing the ZLB unconventional monetary policy. Therefore, once the initial period of the turning points sequence is detected, the counter-factual simulation

\footnotetext{
${ }^{18}$ Here a word of caution is in order given that the standard use of this algorithm is based on GDP data whereas we employ it to detect turning points in the variation of unemployment, because this is our main variable of interest.
} 
Table 4: Average employment rates under standard Taylor rule and ZLB scenario

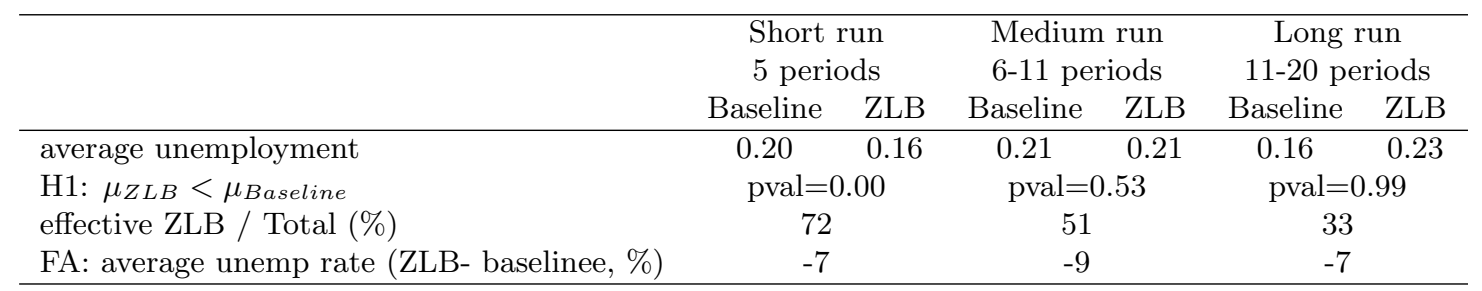

implements a ZLB scenario. The unemployment rate is used as the reference variable to compare the relative performances of the two monetary policy scenarios.

Results are shown in Table 4 . We found 481 events with the same sequence of turning points in the unemployment rate series throughout MC simulations. More precisely, in these cases we detected the same structure of the business cycle as proxied by the evolution of the unemployment rate. ${ }^{19}$ In Table 4 three average measures of the unemployment rate for both the standard Taylor rule and the unconventional monetary policy scenarios are reported, highlighting the effects of monetary policy over different time horizons.

Unemployment rates under the 5 periods ("short run") scenario are calculated as the average of the unemployment rates in the 6 periods after the initial period of investigation, that is the first period detected by the turning points algorithm. ${ }^{20}$ Average unemployment is then calculated also within the time interval from 6 to 11 periods ("medium run" scenario) after the

\footnotetext{
${ }^{19}$ This does not mean that all the other variables within the same simulation follow precisely the same pattern (or even a similar one). Indeed, given the complex structure of the agent-based model, what happens is that the evolution of other variables may differ from each another. For this reason, we decided to follow a "conservative" approach in searching for exactly the same pattern in unemployment across multiple simulations, independently of the evolution of other series.

${ }^{20}$ More specifically, we choose the 6 th period because this represents the beginning of the second increase of unemployment within the double dip episode that the central bank would like to avoid through the unconventional monetary policy.
} 
initial period of investigation and, lastly, for the time span 11-20 ("long run" scenario). On average, in the short run the gain from a ZLB policy is $4 \%$ of reduction in unemployment, with more than $70 \%$ of episodes that effectively reduce the unemployment rate with respect to the baseline scenario. The power of unconventional monetary policy tends to fade away when we move to the medium and the long run. Indeed, while over the "medium run" the fraction of successful cases is still around $50 \%$, in the "long run" it declines to around $1 / 3$ of the 481 detected episodes. In Table 4, we report also the p-values of a one-tail test to assess whether the unemployment rate under the ZLB policy is statistically smaller than the corresponding value under the baseline scenario: ${ }^{21}$ this is the case only over the short-run. ${ }^{22}$

It is worth noting that, while the likelihood of unconventional monetary policy being effective declines as time elapses, in the remaining successful cases it is still effective in reducing unemployment: indeed, the differences between the average unemployment rates between the baseline and the ZLB scenarios are $-7 \%,-9 \%$, and $-9 \%$, respectively, in the short, medium and long run. ${ }^{23}$ This means that when the ZLB policy is successful in reducing unemployment, it preserves the intensity of its effect on unemployment well beyond the short run. However, we have also to stress that when the ZLB policy does not work as supposed, this leads to an unemployment rate

\footnotetext{
${ }^{21}$ In particular, we calculated the average unemployment rate across the 481 simulations, over the three time spans, with and without the ZLB policy, and test the difference netween the two scenarios at $1 \%$ significance.

${ }^{22}$ We also simulated the model without the financial accelerator mechanism. The unemployment rates across 1000 Monte Carlo replications are the following: $19 \%, 21 \%$, and $15 \%$, in the short, medium and long run, respectively, under the baseline scenario; 16 $\%, 21 \%$, and $23 \%$ with the ZLB policy. Not surprisingly, the results are the same when the central bank follows an unconventional monetary policy, given that in both cases the interest rate is at the ZLB. When the central bank follows a standard Taylor rule, the absence of interest rate spreads results in an average unemployment rate slightly lower than in the case in which the financial accelerator is at work. This means that the financial accelerator is useful to generate spread dynamics, as observed in data, but also that such a mechanism is not the central one to explain the relationship between monetary policy and large-scale crises event, whereas the policy rate is the main determinant of potential double dip episodes according to a standard Taylor rule.

${ }^{23}$ The average differences between the two scenarios are calculated only on simulations in which unconventional monetary policy is effective in reducing unemployment.
} 
even higher than in the baseline scenario and a trade-off between short run vs. long-run effects of the unconventional monetary policy emerges. Given the low percentage of success in contrasting unemployment in the long-run (around $1 / 3$ of total cases), the significant increase of the unemployment rate beyond the medium-run, and the result of the statistical test on the average unemployment rates, the effectiveness of the ZLB policy is confined (not surprisingly) to the short-run and something else is needed to lower unemployment beyond the short-run (if this is the goal of economic policy). This is a point that would need further investigation. Broadly speaking, it seems that in some cases a further policy intervention, through for instance fiscal expansion, would be invoked from this analysis.

Overall, the unconventional monetary policy we consider in the computational experiment is quite effective in contrasting unemployment in the short-run by avoiding a "double dip" episode, namely a new rise of unemployment due to a policy rate hike (as would be implied by a standard Taylor rule). The likelihood of a positive effect of a ZLB policy (namely the number of successes in contrasting unemployment with respect to the total number of "double dip" episodes) decreases as time elapses, while its intensity is preserved in the cases in which the ZLB policy works effectively. Therefore, monetary policy can be usefully employed as a tool for contrasting unemployment especially in the short run, but it cannot be considered as the only or the main remedy to unemployment, particularly over longer time horizons.

\section{Concluding remarks}

This paper contributes to the growing literature on the post crisis behavior of monetary authorities. In order to do that we built an ABM model with a financial accelerator mechanism like in Bernanke et al. (1999). The simulations show that a scenario where the central bank is able to keep the 
short term interest rates very close to the zero lower bound for an extended period of time can help the economy to better react to large crisis events, at least in the short run. Such intervention can potentially avoid a "double dip" recession where a fragile recovery is hampered by a premature increase of the policy rate by the central bank.

As stated by Howitt (2012), ABM can be used by the policy makers alongside with the traditional DSGE models allowing them evaluate the possible policy implications from a different perspective based on an alternative methodology. Moreover, ABM are particularly useful for the analysis of crisis episodes. Indeed, the ABM approach is well equipped to investigate the effects of heterogeneity and direct interaction, as for instance in the case of financial contagion. Accordingly, the failure of one or more firms can damage the bank's balance sheet through non-performing loans that, in turn, may influence the financing conditions of surviving firms, and so on, giving rise to a (positive feedback) vicious circle. In other words, ABMs can be used to reproduce the endogenous tendency of the system towards the crisis and then to experiment the effectiveness of policy measures to prevent it or at least to mitigate its consequences.

In this context, our contribution can be viewed as one of the first attempts to evaluate unconventional monetary policies in a framework different from the standard DSGE model. ${ }^{24}$ In particular, the novelty of our computational approach is related to the combination of (i) pattern search (by applying an algorithm to detect business cycle turning points), that allows us to isolate specific time intervals characterized by double dip episodes that endogenously emerge in the model, and (ii) counter-factual simulations, to assess the role of unconventional monetary policy. The main result is that monetary policy, by keeping the policy rate near to the ZLB as long as nec-

\footnotetext{
${ }^{24}$ However, there other contributions in the ABM field that investigate both microprudential and macroprudential policies. Strictly speaking, we cannot include them in the narrow definition of unconventional monetary policy.
} 
essary, can be an effective tool for avoiding the rise of unemployment that would be implied by following a Taylor rule-like behavior in response to a timid recovery. We presented this result by commenting the differences between a basic scenario in which the central bank follows a standard Taylor rule and an alternative scenario in which a ZLB unconventional monetary policy is implemented. The unconventional monetary policy is effective in the majority of cases in which a "double dip" recession episode would be emerged based on a Taylor rule behavior. It is worth noticing, however, that the effectiveness of monetary policy tends to vanish as time elapses. This means that monetary policy cannot be considered as the only or the main policy tool for contrasting the rise of unemployment and, in general, to improve the macroeconomic performances, especially in the medium and long run. Moreover, some other relevant factors are out of the analysis though they could have a relevant impact on the results of the policy experiment: let's think for instance to the making of bubbles, especially when interest rates are low for long periods of time, that could limit the effectiveness of the ZLB unconventional monetary policy.

Many potential issues are not covered in this contribution and they are left for further research. A first class priority will be to conduct a dip comparison between the standard financial accelerator mechanism and the new agent-based version in order to understand similarities and differences in a systematic way. Moreover, the model can be used to explored large crises that do not burst in the financial sector but that occurred in the real side of the economy. Related to the above critical discussion on the limit of unconventional monetary policy, the tendency to the building of financial bubbles in a low interest rates scenario should be considered as a a major factor to be included in the analysis, along with the rise of inequality and its macroeconomic implications. 
Acknowledgment The authors would like to thanks the participants to the 20th Workshop on Economics with Heterogeneous Interacting Agents (WEHIA), Sophia Antipolis, May 21-23, 2015, two anonymous referees and the Guest Editor Mauro Napoletano for valuable comments and suggestions. The research leading to these results received funding from the European Union, Seventh Framework Programme FP7, under grant agreement FinMaP n0: 612955. 


\section{References}

Bernanke, B. S., 2005. The economic outlook. Speech 90, Board of Governors of the Federal Reserve System (U.S.).

Bernanke, B. S., Gertler, M., Gilchrist, S., June 1999. The financial accelerator in a quantitative business cycle framework. In: Taylor, J. B., Woodford, M. (Eds.), Handbook of Macroeconomics. Vol. 1 of Handbook of Macroeconomics. Ch. 21, pp. 1341-1393.

Boeckx, J., Dossche, M., Peersman, G., February 2017. Effectiveness and Transmission of the ECB's Balance Sheet Policies. International Journal of Central Banking 13 (1), 297-333.

Bordo, M. D., Landon-Lane, J., Oct. 2013. Does Expansionary Monetary Policy Cause Asset Price Booms; Some Historical and Empirical Evidence. NBER Working Papers 19585, National Bureau of Economic Research, Inc.

Brunnermeier, M. K., Schnabel, I., 2016. Bubbles and Central Banks: Historical Perspectives. Cambridge University Press, Cambridge, UK.

Brzoza-Brzezina, M., Kolasa, M., Makarski, K., 2013. The anatomy of standard dsge models with financial frictions. Journal of Economic Dynamics and Control 37 (1), 32-51.

Burlon, L., Gerali, A., Notarpietro, A., Pisani, M., Jul. 2016. Macroeconomic effectiveness of non-standard monetary policy and early exit. A model-based evaluation. Temi di discussione (economic working papers), Bank of Italy, Economic Research and International Relations Area.

Chen, H., Curdia, V., Ferrero, A., November 2012. The Macroeconomic Effects of Large scale Asset Purchase Programmes. Economic Journal 122 (564), 289-315. 
da Silva, M. A., Lima, G. T., 2015. Combining monetary policy and financial regulation: an agent-based modeling approach. Working Paper 394.

Delli Gatti, D., Gaffeo, E., Gallegati, M., 2005. The apprentice wizard: Monetary policy, complexity and learning. New Mathematics and Natural Computation 1 (1), 109-128.

Delli Gatti, D., Gallegati, M., Greenwald, B. C., Russo, A., Stiglitz, J. E., 2012. Mobility constraints, productivity trends, and extended crises. Journal of Economic Behavior \& Organization 83 (3), 375-393.

Dosi, G., Fagiolo, G., Napoletano, M., Roventini, A., Treibich, T., 2015. Fiscal and monetary policies in complex evolving economies. Journal of Economic Dynamics and Control 52 (C), 166-189.

Ferrero, A., 03 2015. House Price Booms, Current Account Deficits, and Low Interest Rates. Journal of Money, Credit and Banking 47 (S1), 261-293.

Fratianni, M., Giri, F., Dec. 2017. The Tale of Two Great Crises. Journal of Economic Dynamics and Control, Elsevier, vol. 81(C), pages 5-31.

Gerali, A., Neri, S., Sessa, L., Signoretti, F. M., 09 2010. Credit and banking in a dsge model of the euro area. Journal of Money, Credit and Banking 42 (s1), 107-141.

Gertler, M., Karadi, P., January 2011. A model of unconventional monetary policy. Journal of Monetary Economics 58 (1), 17-34.

Gilchrist, S., Zakrajsek, E., June 2012. Credit Spreads and Business Cycle Fluctuations. American Economic Review 102 (4), 1692-1720.

Gordon, R. J., Wilcox, J. A., 1981. Monetarist interpretations of the great depression: An evaluation and critique. In: The great depression revisited. Martinus Nijhoff Publishing. 
Haber, G., 2008. Monetary and fiscal policy analysis with an agent-based macroeconomic model. Jahrbucher fur Nationalokonomie und Statistik $228(2-3), 276-295$.

Harding, D., Pagan, A., March 2002. Dissecting the cycle: a methodological investigation. Journal of Monetary Economics 49 (2), 365-381.

Howitt, P., 2012. What have central bankers learned from modern macroeconomic theory? Journal of Macroeconomics 34 (1), 11-22.

Kiyotaki, N., Moore, J., April 1997. Credit cycles. Journal of Political Economy 105 (2), 211-48.

Minsky, H. P., 1986. Stabilizing an unstable economy. Yale University Press New Haven.

Lengnick, M., Wohltmann, H. W.,2016. Optimal monetary policy in a new Keynesian model with animal spirits and financial markets. Journal of Economic Dynamics and Control, Elsevier, vol. 64(C), 148-165.

Quadrini, V., 2011. Financial frictions in macroeconomic fluctations. Economic Quarterly (3Q), 209-254.

Riccetti, L., Russo, A., Gallegati, M., 2013a. Leveraged network-based financial accelerator. Journal of Economic Dynamics and Control 37 (8), $1626-1640$.

Riccetti, L., Russo, A., Gallegati, M., 2013. Unemployment benefits and financial leverage in an agent based macroeconomic model. Economics The Open-Access, Open-Assessment E-Journal 7, 1-44.

Riccetti, L., Russo, A., Gallegati, M., October 2015. An agent based decentralized matching macroeconomic model. Journal of Economic Interaction and Coordination 10 (2), 305-332. 
Romer, C. D., 1990. The great crash and the onset of the great depression. Quarterly Journal of Economics 105, 597-624.

Salle, I., Yildizoglu, M., Senegas, M.-A., 2013. Inflation targeting in a learning economy: an abm perspective. Economic Modelling 34 (C), 114-128.

Taylor, J. B., December 1993. Discretion versus policy rules in practice. Carnegie-Rochester Conference Series on Public Policy 39 (1), 195-214.

Taylor, J. B., Jan. 2009. The Financial Crisis and the Policy Responses: An Empirical Analysis of What Went Wrong. NBER Working Papers 14631, National Bureau of Economic Research, Inc.

Temin, P., 1976. Did monetary forces cause the Great Depression. MIT Press.

Weale, M., Wieladek, T., 2016. What are the macroeconomic effects of asset purchases? Journal of Monetary Economics 79 (C), 81-93. 


\section{A-1 Data appendix}

Policy rate: Effective Federal Funds Rate (FEDFUNDS), percentage, non seasonal adjusted.

Corporate loans rates: Baa corporate bond yields (BAA), percentage, non seasonal adjusted.

Consumer price index: Consumer Price Index for All Urban Consumers: All Items (CPIAUCSL), 1982-84=100, non seasonal adjusted.

Unemployment rate: Civilian Unemployment Rate (UNRATE), percentage, seasonal adjusted.

Gross domestic product: Gross Domestic Product (GDP), Billions of US Dollars, SAAR.

\section{A-2 Matching mechanism}

As already explained, the model is an extension of the model proposed by Riccetti et al. (2013, 2015). Here we describe the matching mechanism developed in the cited papers and applied in the current paper in three markets: labor market, capital goods market, and consumption goods market. The mechanism is general because we always have two classes of agents that interact, that is the demand and the supply sides. Each agent in the demand side observes a list of potential counterparts in the supply side and chooses the most suitable partner; in this paper, given that we have homogeneous goods and workers, "the most suitable partner" is the one with the lowest price. The price is set by the supply side, according to a simple rule that accounts for the "sale" of the previous period (for instance, if the consumption good producer sold all its output, perhaps it set a low price, then it tries to increase it. Instead, if it has many inventories, perhaps the price was 
too high and it has to reduce it). However, every market has its peculiar aspects, therefore the choice of the price mechanism and of the most suitable partner is done according to some market-specific criteria.

In particular, the interaction process develops as follows:

- a random list of agents on the demand side is set.

- The first agent in the list observes a random subset of potential counterparts on the supply side and chooses the cheapest one. For instance, in the consumption goods market, the household extracted at the top of the demand side list observes some firms that sell consumption goods and, if the household has enough money, buy the good sold at the lowest price among the observed firms. The probability that an agent on the supply side is observed is given by parameter $0<\chi \leq 1$, that proxies the degree of imperfect information. In other words, the agent in the demand side extracts a number for each potential partner, if the number is below the value $\chi$, the agent in the supply side is observed.

- The second agent on the list performs the same activity on a new random subset of the updated potential partner list. The list is updated because, using again the consumption goods market as an example, if the firm that sold the goods to the first agent do not have further goods to be sold, it is deleted from the potential partner list of the supply side.

- The process iterates until the end of the demand side list. In our example, it happens when all households buy one consumption good or when some households do not buy one consumption good because they do not have enough money to buy it.

- A new random list of agents in the demand side is set and the whole 
matching mechanism continues. Indeed, in our example, some households could try to buy more than one good. However, the list is new in order not to always favor the same household that can choice the partner first. Indeed, although the degree of imperfect information, when the mechanism proceeds, the agents in the supply side that require the lowest prices tend to finish, while the agents with the higher prices remain.

- The process ends when either one side of the market (demand or supply) is empty or no further matchings are feasible because the highest bid (for example, the money still available to the richest household) is lower than the lowest ask (for example, the lowest price asked by firms with unsold goods).

\section{A-3 Sequence of events}

The sequence of events runs as follows.

- At the beginning of each period, new entrants substitute bankrupted agents according to a one-to-one replacement. ${ }^{25}$

- Workers update their desired wage: upwards if employed in the previous period, downwards otherwise; however, the desired wage has a lower bound tied to the price of one consumption good.

- Firms update their selling prices: upwards if the firm sold all its output in the previous period, downward if it has inventories; however, the price can not go below the average cost of production.

\footnotetext{
${ }^{25}$ The initial net worth is related to the average price of consumption goods and capital goods, respectively, for the two types of firms; if the banking sector fails then an initial net worth, tied to the firms' net worth, is given to the new bank. The total amount of resources needed to finance new entrants is subtracted from the flow of dividends to be distributed to households (and only the remaining part is actually distributed); in the case total dividends are not enough to cover the total net worth of entrants, the government intervenes paying the needed difference.
} 
- The government updates the tax rate on agent's income according to the evolution of the ratio between public debt and GDP.

- The central bank sets the policy rate according to the Taylor rule.

- The capital goods owned by consumption goods producers depreciate.

- Firms set their desired production based on past production, expected profitability and the level of inventories.

- Based on desired production and given the expected price of capital, consumption goods producers derive total financing; the demand for credit is then given by total financing less internal resources, plus the possible expiring debt.

- Based on desired production and given the consequent expected wage bill, capital producers derive total financing; then, the demand for credit is given by total financing less available liquidity or plus the possible expiring debt.

- The banking system sets the supply of credit as a multiple of its net worth; in particular, credit supply increases (decreases) as the bank's profit increases (decreases). Moreover, the banking system sets interest rates by charging a risk premium on firm loans which increases when firm leverage increases. The risk premium gives rise to the financial accelerator mechanism.

- The credit market opens: the demand of credit comes from both capital and consumption goods producers. In the case the demand is higher than the supply, firms are credit rationed proportionally.

- Firms' liquidity is then computed as the sum of both internal and external resources. In the case firms' liquidity is negative, that is the 
firm does not receive a loan at least equal to cover the expiring debt, it goes bankrupt.

- Insolvent as well as illiquid firms are declared bankrupted; the banking system suffers non-performing loans for the fraction of loans not repaid by firms; moreover, the bank comes into the possession of firms' inventories of capital and consumption goods, that it tries to sell at a discounted price in the respective markets.

- Based on available liquidity, capital goods producers derive their labor demand and consumption goods producers derive their capital goods demand.

- The labor market opens between capital goods producers and the government (demand side) and households (supply side). First of all, the government hires a fraction of households picked at random from the whole population. The remaining part of households follows the decentralized matching process, being available for working in private capital goods firms.

- Employed workers get their wage on which they pay a proportional tax.

- Capital goods are produced by hired workers; current production plus inventories are available on the market to be sold to consumption goods producers.

- The capital goods market opens and a decentralized matching between capital goods producers and the banking system (supply side) and consumption goods producers (demand side) takes place.

- Consumption goods are produced by employing capital goods; current production plus inventories is available on the market to be sold to households. 
- Based on available income and wealth, household set the amount available to buy consumption goods.

- The consumption goods market opens and a decentralized matching between consumption goods firms and the banking system (supply side) and households (demand side) takes place.

- Firms compute their profits on which they pay a proportional tax; a fraction of net profits is distributed as dividends to households; then, firms' net worth is updated.

- The banking sector computes its profit on which it pays a proportional tax; a fraction of the net profit is distributed as dividends to households; then, the net worth of the banking sector is updated.

- Households' saving is deposited in the banking system and (in the next period) gives rise to the payment of an interest on which depositors pay a proportional tax; households also pay a wealth tax according to a proportional tax rate.

- The public deficit and the public debt are computed. Government securities (in the next period) are bought by the banking sector; in the case the private demand for these bonds is below the supply, the central bank buys the difference.

- Depending on the balance sheet of the banking sector, the central bank either provides money injections or receives reserves. 